\title{
The Proposition of an EI Equation of Square and L- Shaped Slender Reinforced Concrete Columns under Combined Loading
}

\author{
Leila Hamzaoui \\ LGC-ROI, Civil Engineering Laboratory, Risks and \\ Structures Interactions \\ Faculty of Science \\ University of Batna 2 \\ Batna, Algeria \\ 1.hamzaoui@univ-batna2.dz
}

\author{
Tayeb Bouzid \\ LGC-ROI, Civil Engineering Laboratory, Risks and \\ Structures Interactions \\ Faculty of Science \\ University of Batna 2 \\ Batna, Algeria \\ tayeb.bouzid@univ-batna2.dz
}

\begin{abstract}
The stability and strength of slender Reinforced Concrete (RC) columns depend directly on the flexural stiffness EI, which is a major parameter in strain calculations including those with bending and axial load. Due to the non-linearity of the stress-strain curve of concrete, the effective bending stiffness EI always remains variable. Numerical simulations were performed for square and L-shaped reinforced concrete sections of slender columns subjected to an eccentric axial force to estimate the variation of El resulting from the actual behavior of the column, based on the moment-curvature relationship. Seventy thousand (70000) hypothetical slender columns, each with a different combination of variables, were used to investigate the main variables that affect the EI of RC slender columns. Using linear regression analysis, a new simple and linear expression of $E I$ was developed. Slenderness, axial load level, and concrete strength have been identified as the most important factors affecting effective stiffness. Finally, the comparison between the results of the new equation and the methods proposed by ACI-318 and Euro Code-2 was carried out in connection with the experimental results of the literature. $A$ good agreement of the results was found.
\end{abstract}

Keywords-flexural stiffness; reduction factor; reinforced concrete; rigidity; slender columns

\section{INTRODUCTION}

For a bi-articulated column supporting a load $P$ applied with an eccentricity $e$, the corresponding moment which is equal to P.e is called the "first order moment". Under the action of this moment the column deforms in simple curvature and the bending moment is at its maximum at half height and equal to $M=P . e+P . \Delta$.The increase of the latter caused by the displacement $\Delta$ is called the $P \Delta$ effect or second order moment. The longer the column is compared to its cross section, the greater the lateral displacements will be and the greater the second order moment will be. Buckling failure will occur under a lower resistance than that which would have caused the short column to fail. In this case, the strength of slender Reinforced Concrete (RC) columns is remarkably reduced. Several factors contribute to this reduction. In addition to the $P \Delta$ effect, shrinkage, creep, and cracking occur along the length of the column and are directly related to the supported part of the compressive stress block in the concrete. Leonhard Euler who based his work on Hook's law and the moment-curvature relationship studied the buckling problem. He developed (1) to predict the minimum buckling load of a perfect column:

$$
p c r=\frac{\pi^{2} E I}{l^{2}}
$$

This equation did not depend on the strength of the crosssection but rather on the bending stiffness $E I$. It was valid only if the moment of buckling obeys Hook's law, where the retained stiffness is constant. This is the case of a homogeneous isotropic and elastic material but this is not the case for reinforced concrete columns whose behavior in practice becomes clearly non-linear at the level of the descending branch of the $\sigma-\varepsilon$ curve, therefore the buckling takes place in the non-linear domain. Euler's expression remains valid if the bending stiffness is replaced by a value representative of the effective stiffness at the moment of failure which is either with the crushing material (case of short columns) or with buckling (case of thin columns). During the loading and due to the inelastic behavior depicted by the stress/strain curve of concrete the value of the $E I$ varies at each point along the section. The difficulty to choose a single value of $E I$ appears because some methods consider that the column stiffness is constant along the section and the length of the column, when in addition it is necessary to consider shrinkage, creep, and lateral deflection. If we introduce the effects of concrete cracking, this can cause a large variation in bending stiffness. The objective of this work is to develop an analytical model for the study and analysis of the non-linear material and geometrical behavior of slender reinforced concrete columns of square and "L" cross-section under axial load and biaxial bending in order to find a simple relationship explicitly describing the real behavior of the effective bending stiffness $E I$ as a function of parameters such as concrete strength $f c$, steel yield strength $f y$, cross-sectional dimensions, percentage of reinforced steel $\rho$, and column length $L$. In addition, this 
stiffness is compared with experimental test results from the literature and design codes ACI-318 [1] and EC-2 [2]. The studied columns were bent into a single symmetrical curvature, in non-oscillating frames subjected to short-term loads.

The behavior of RC slender columns under axial loads and bending moments in the two main planes of inertia is of great interest for structural analysis and design .The difficulty in this case is in the fact that it is not possible to give a general mathematical formulation as in the case of uniaxial bending because the position of the neutral axis is not known in advance. The difficulty increases if the cross-section of the column is not symmetrical, and increases even more if the behavior law $(\sigma-\varepsilon)$ is not linear. Some researchers have proposed an iterative method initiated in [3] which consists of establishing by successive trials the neutral axis for which the internal forces in the section are in equilibrium with the external loads. Other methods, based on the determination of interaction curves, interaction surfaces or interaction contours for loading, were used for calculation and verification [4]. In most computer programs for reinforced concrete structures, there are indications of the limit state justification of square and rectangular columns while the L-shaped cross-section is not treated. It is therefore interesting to fill in the gaps in the equations presented in the literature because they are valid only for ordinary sections, and in practice, there are sections of different shapes such as tee $(\mathrm{T})$, simple cross $(+)$, hexagonal or thin-walled boxes, and finally L-shaped. In fact, the latter presents several difficulties like the absence of vertical and horizontal axes of symmetry.

\section{LITERATURE REVIEW}

Flexural rigidity is a necessary component in the estimation of the deflection of RC elements subjected to bending moment and axial loading, especially slender columns. It should be noted that the deflection is important because it has a direct and strong influence on the second order moments induced by the axial loads. Recently, major progress has been made in the development of nonlinear methods for the analysis of slender RC columns. Numerous methods are used to evaluate the bending stiffness $E I$ taking into account all the factors that contribute to its decrease at the level of the concrete stress block in compression (non-linear material behavior) and at the level of the lateral displacement length of the column (nonlinear geometric behavior) to determine the critical buckling load nearest to the effective values. Accordingly, the effective bending stiffness of columns under short-term loading can be expressed as: $E I=\alpha . E c . I c+E s$.Is where $\alpha$ is the stiffness reduction factor, $E c$ and $E s$ are the elasticity modulus of concrete and steel respectively, $I c$ and $I s$ are the moments of inertia of the cross-section of concrete and steel about the central axis of the cross-section respectively. After determining the factor $\alpha$, the $E I$ can be easily calculated. The factor $\alpha$ is a function of the material properties, the steel ratio, the axial load, and other parameters. This reduction factor of bending stiffness has been evaluated and studied by a number of researchers and some current codes and according to [1], is always taken equal to 0.2 for columns. The Eurocode EC-2 [2] is provided with a coefficient of flexibility $K e$ which is a function of a set of parameters such as: the relative normal force $v$, the mechanical slenderness $\lambda_{m}$, the geometric reinforcement ratio $\rho$, the creep rate $\varphi_{\text {eff }}$, and the characteristic strength of the concrete compression cylinder at 28 days $f_{c k}$. Many formulations have been proposed in the literature. Authors in [5-7] have presented statistical evaluations of the flexural rigidity of RC columns and of rectangular crosssections of composite RC columns. Authors in [8] proposed a reduction coefficient as a function of various parameters such as slenderness ratio $(L / h)$, eccentricity ratio $(e / h)$, and axial load ratio $\left(P / P_{0}\right)$. Authors in [6] proposed a general expression to obtain an effective flexural stiffness applicable to any crosssectional shape under short or long-term biaxial eccentric loading for normal and high concrete strength. Authors in [9] proposed a study for the reduction factor of the RC column with equi-axial $\mathrm{T}$ section and in [10] dealt with the crossshaped cross-section. Authors in [11] presented new expressions for a beam with rectangular and T-shaped crosssections, square, rectangular and circular cross-sections for columns in function of concrete strength $f c$, steel percentage $\rho$, and level of charge $P / P_{0}$. Authors in [12] presented their approach to find effective flexural stiffness for circular columns. In this research, the stiffness reduction factor was suggested to treat slender square and L-section columns with equal flanges. Some researchers have conducted studies on eccentrically loaded L-sections. Authors in [13] presented an experimental and analytical research on the load carrying capacity of L-shaped RC columns with equal and unequal flanges. Authors in [14] carried out a theoretical study on the calculation of $\mathrm{L}$ and square sections by the interaction approach. Authors in [15] based their study on the finite element method to analyze and draw the interaction surfaces of $\mathrm{L}$ and square sections. An interesting research concerning the behavior of L-section and square composite columns under biaxial eccentric loading according to different laws of concrete behavior is presented in [16]. Authors in [9] studied the L section with equal flanges and suggested a formula for the bending stiffness reduction factor of slender RC columns under different axial load levels and different seismic action levels. The current work is a contribution in this field of study and, in addition, a proposition of a simple solution for the calculation and verification of thin columns is presented.

\section{ANALYSIS METHOD}

In order to study the effective bending stiffness values of the slender RC column under combined biaxial bending and axial loading, nonlinear computer analysis was developed. Material and geometric nonlinearity were included in the research study for $\mathrm{L}$ and square sections. It should be noted that articulated end columns with equal load eccentricities at the ends acting in the same plane have been taken in account. The analysis can be divided into three parts: (a) the cross-sectional strength (analysis of cross section), (b) the effect of slenderness on the column strength (analysis of second order), (c) the third and main objective is the development of a new formula for estimating the $E I$ bending stiffness of slender biaxially loaded $\mathrm{RC}$ columns in which these factors are included.

\section{A. Material Behavior and Assumptions}

The studied columns are all made of RC. This composite material consists of two elements with different characteristics. 
In order to simulate the non-linear analysis of the complete response of RC columns of square and L-shaped cross-sections with equal flanges under biaxial bending and compression, a computer program compiled by an integral numerical method was used, based on the following assumptions:

- Plane sections before bending remain plane after bending.

- The tensile strength of concrete is neglected, and the stressstrain curve of concrete in compression refers to the unconfined diagram in [17], as shown in Figure 1(a), whose curve characteristics are calculated using (2) and (3):

$$
\begin{gathered}
\sigma=f c\left[\left(2 \cdot \frac{\varepsilon c}{\varepsilon c 0}\right)-\left(\frac{\varepsilon}{\varepsilon c 0}\right)^{2}\right] \\
\text { for } 0 \leq \varepsilon_{\mathrm{c}} \leq \varepsilon_{\mathrm{c} 0}=0.002 \\
\sigma=f c[1-Z u(\varepsilon c-\varepsilon c 0)] \\
\text { for } \varepsilon_{c o} \leq \varepsilon_{c} \leq \varepsilon_{c u}=0.004
\end{gathered}
$$

with:

$$
\mathrm{Zu}=\frac{0.5}{\varepsilon 50 \mathrm{u}-\varepsilon \mathrm{co}}, \quad \varepsilon_{50 \mathrm{u}}=\frac{3+0.285 . \mathrm{f}_{\mathrm{c}}}{142 \mathrm{f}_{\mathrm{c}}-1000}, \varepsilon_{50 \mathrm{u}} \geq \varepsilon_{\mathrm{co}}\left(f_{c} \mathrm{mpa}\right)
$$

- The stress-strain curve of steel is taken as the usual bilinear relationship shown in Figure 1(b).

The section is divided into a number of small fiber elements. The concrete element stress distribution is also divided into a number of small fiber elements. Concrete shrinkage and creep are ignored.

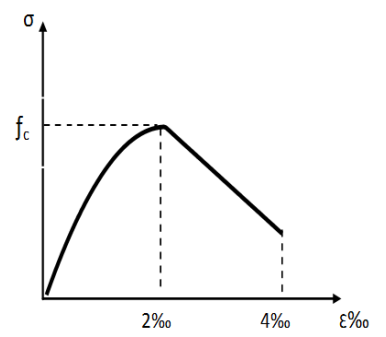

(a)

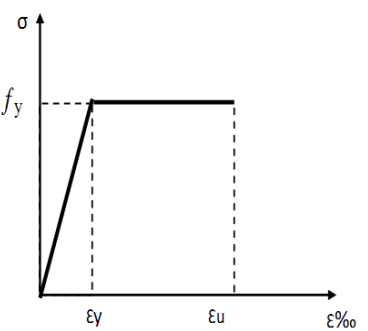

(b)
Fig. 1. Concrete and steel $\sigma-\varepsilon$ diagram

\section{1) Cross Section Analysis}

This work presents an indirect method for the analysis of the ultimate limit states of RC columns of L and square crosssections subjected to biaxial loading. We consider a square section of dimensions $B \times B$, and another square section of dimensions $B_{1} \times B_{1}$ with $B_{1}<B$ being away from the corner of the original square $(B \times B)$. Removing the section $B_{1} \times B_{1}$ results in an L-shaped section, as shown in Figure 2(a). For different values of $B_{1}$, we can obtain different dimensions of the Lsection. If $\left(B_{I}=0\right)$ the L-section becomes a square section. The ratio $(B 1 / B)$ varies from 0 to 0.6 . It is assumed that the steel reinforcement is evenly distributed around the perimeter of the cross-section (see Figure 2(b))[14].

\section{2) Internal Forces}

The cross section is divided into infinitely small slices (see Figure 3). For each one of them, the internal forces (concrete, compression reinforcement and tensile reinforcement) are evaluated to give finally an axial load and an ultimate moment. The resulting axial load and the resulting moment must be equal respectively to the sum of the internal loads and the sum of elementary moments.

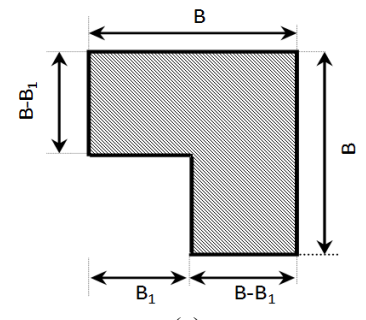

(a)

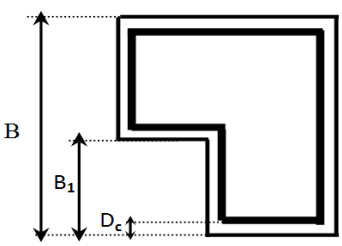

(b)
Fig. 2. L cross section and steel reinforcement distribution.

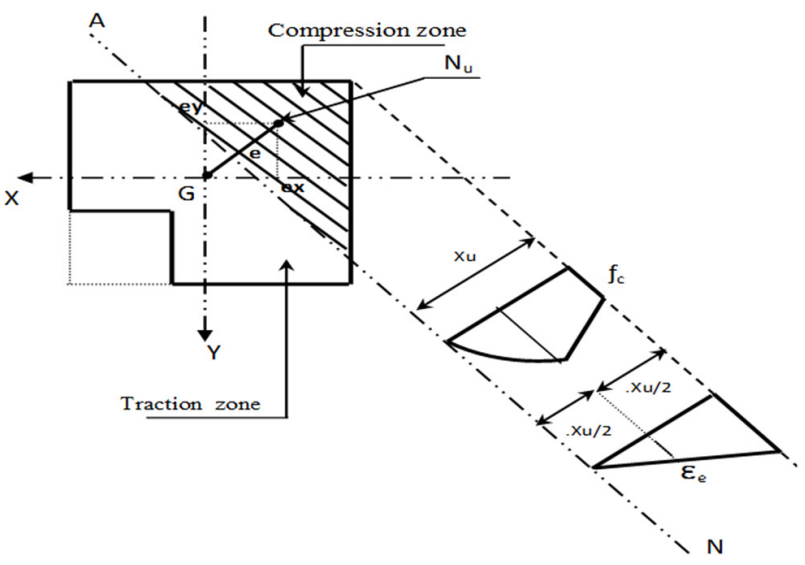

Fig. 3. L cross section subjected to biaxial load.

The resulting axial load and the resulting moment are equal respectively to the sum of the loads and elementary moment shown in (4), and (5):

$$
\begin{gathered}
P=\sum_{i=1}^{n} f_{c} \cdot A_{c i} \cdot \sum_{i=1}^{n}\left(f_{y}-f_{c}\right) \cdot \rho \cdot \frac{A_{c i}}{100} \\
M=\sum_{i=1}^{n} f_{c} . Y_{c i} \cdot A_{c i} \cdot \sum_{i=1}^{n}\left(f_{y}-f_{c}\right) \cdot \rho \cdot Y i \cdot \frac{A_{c i}}{100}
\end{gathered}
$$

where $n$ is the number of slices, $A_{c i}$ is the concrete area of the slice $I, \rho=(A s / A c) .100$ presents the percentage of longitudinal reinforcement, $A s$ is the area of longitudinal reinforcement, and $Y i$ is the distance from the edge of steel to the center of the section.

Analysis is done by sweeping the section parallel to the neutral axis. For the L-shaped section, the computer program studies different positions of the neutral axis according to the angle of inclination $\theta$, where $\theta=\operatorname{tang}^{-1}(e x / e y)$ with $e x$ and $e y$ being the eccentricities along the $x$ and $y$ axis respectively. The computer analysis has been prepared by considering the axis of bending. Figure 4 explains these cases:

- Case 1: Uniaxial bending, angle of inclination $\theta=0^{\circ}$.

- Case 2: Uniaxial bending, angle inclination $\theta=90^{\circ}$. 
- Case3: Biaxial bending, angle of inclination $0<\theta<45^{\circ}$.

- Case4: Biaxial bending, angle of inclination $45^{\circ}<\theta<90^{\circ}$.

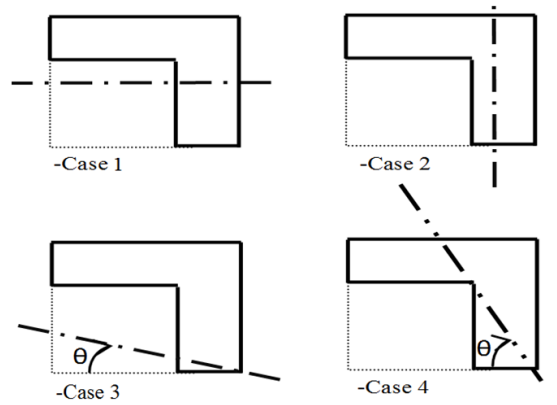

Fig. 4. The four cases of uniaxial and biaxial load.

The codes of the above mentioned cases were developed in FORTRAN and were used to obtain the ultimate resistance $P u$ and moments $M u$ as results of the different positions of the neutral axis. The input data include the size of the square $B_{1}$, the depth $B$ of the section, the depth of embedding $D c$, the characteristic strengths of concrete $f c$ and steel $f y$, the moduli of elasticity of steel $E s$ and concrete $E c$, the angle of inclination $\theta$, and the percentage of reinforcement $\rho$.

\section{SECOND ORDER ANALYSIS}

Columns with a moderate slenderness may have their secondary moments determined with an approximate analysis such as the moment magnifier method which is used in this study. This procedure uses a moment magnification factor $\delta$ to amplify the applied moment $M_{a}$ sufficiently for the account of secondary moments and to ensure safe design. For columns subjected to axial loading and equal and opposite end moments, the maximum bending moment can be taken as:

$$
M c=\delta \cdot M a
$$

where:

$$
\delta=\frac{1}{1-\frac{P}{P c r}}
$$

where $M_{c}$ is the design bending moment that includes secondorder effects, $M_{a}$ is the applied column bending moment, $P$ is the factored axial load acting on the column, and $P_{c r}$ is Euler's buckling strength. The secondary moment due to the column slenderness is calculated as the difference between the internal resisting moment and the applied moment. For the purpose of analysis, $M_{c}$ is replaced by the cross section bending moment $M_{C S}$, and $M_{a}$ is replaced by the overall column bending moment $\left(M_{c o l}\right)$ as shown in (7):

$$
\text { Mcs }=\left(\frac{1}{1-\frac{P}{P c r}}\right) \cdot \text { Mcol }
$$

\section{CALCULATION OF THE FLEXURAL STIFFNES OF THE COLUMN}

The design of the flexural stiffness as a function of the moment-to-curvature ratio $M / \Phi$ is the most reasonable relation of the EI representation. The analysis studies show various cross-sectional parameters as well as axial loading influencing the bending stiffness. The computer program is structured according to the well-known $(P, M, \Phi)$ relation. A linear strain is assumed and the Kent \& Park relation [17] relates stress to strain. The curvature is calculated directly from the geometry $(\Phi)$ and it is known as the exact value in this computer program and the extreme fiber is assumed to be at crush strain. The depth of the neutral axis $X u$ can be incremented throughout the program to provide the necessary strain variation. Therefore, this depth starts at a small fraction of the total section depth and is increased in defined increments until the maximum of the column capacity in pure axial compression is reached $\left(P_{0}\right)$. The curvature is obtained by dividing the stress of the extreme fiber (usually 0.003 ) by the depth of the compression zone $(\Phi=0.003 / X u)$. Using this curvature and assuming a linear strain distribution, it is possible to find the stress in each fiber. For each increment, the axial load $P$, the bending moment of the cross section $M c s$, and the curvature $\Phi$ are calculated. Equation (1) is used to find the critical load $P_{c r}$ which allows calculating the bending moment of the column $M_{\text {col }}$ through (7) whose slenderness effects were taken into account. The program uses the formulation $M_{c o l} / \Phi$ to calculate the effective bending stiffness of a slender column whose nonlinearities due to $P \Delta$ effects and nonlinear behavior of the material are taken into account at all times.

\section{PROPOSED FORMULA OF THE REDUCTION FACTOR OF FLEXURAL STIFFNESS}

In practice, the engineer often has difficulties to give a reasonable interpretation of the bending stiffness that represents the real behavior of slender RC columns. This stiffness is easy to calculate with the $M / \Phi$ method, which gives satisfactory results, but it is not easy to solve manually making the use of a computer recommended which in this case makes it mandatory but not preferable. In order to simplify the estimation of $E I$ bending stiffness under short-term loads, the well-known equation $E I=\alpha . E c I c+E s I s$ is obtained. Research and expressions have proposed to evaluate the reduction factor or the factor of effective stiffness which is of origin can be expressed by:

$$
\alpha=\frac{E I-E s I s}{E c I c}
$$

Thus, to evaluate the EI flexural stiffness, a simple expression is proposed to avoid sophisticated and complicated calculations. Multiple linear regression approaches, taking into account the simulated theoretical stiffness data, are conducted to evaluate the $E I$ expression. Linear regression is chosen as the method of analysis because the objective is to develop a simple and accurate equation for the reduction factor $\alpha$. This method is very useful in order to determine the effective behavior of certain parameters. For example the work in [18] was based on the same principle to give the equation of effective ductility as a function of shear reinforcement ratio and compressive strength of concrete. In this work the used analysis method consists in finding an expression describing the reduction factor $\alpha$ for different values of concrete strength $f c$, steel yield $f y$, percentage of reinforced steel $\rho$, steel ultimate strength $f y$, L section dimensions, square or equal flanges presented by the ratio $B_{1} / B$, slenderness ratio $L / B$, the neutral axis angle $\theta$ which 
presents the loading angle, and the axial loading ratio $P / P_{0}$, where $P_{0}$ is the strength of the axial compression column under pure axial loading. This regression concerns a column of a square and equal $\mathrm{L}$ section presents the proprieties illustrated in Table I, based on the statistical analysis of the theoretical values of $\alpha$ for all simulated columns in which $P / P_{0}$ ranged from 0.1 to 1 . Over 70000 isolated reinforced concrete columns were simulated to generate the effective stiffness factor. Each simulated column had a different combination of cross section, geometric, and material proprieties.

TABLE I. SPECIFIED PROPERTIES OF STUDIED RC COLUMNS

\begin{tabular}{|c|c|c|}
\hline Proprieties & Specified values & Number of specified values \\
\hline$F \mathrm{c}$ & $15 ; 60$ incr $5 \mathrm{mPa}$ & 10 \\
\hline$F y$ & $200 ; 600$ incr $100 \mathrm{mPa}$ & 5 \\
\hline$B_{1} / B$ & incr 0.1 & 7 \\
\hline$L / B$ & $10 ; 30$ incr 5 & 5 \\
\hline$P$ & $0.5 ; 4 \% \quad$ incr $0.5 \%$ & 8 \\
\hline$\theta$ & $0^{\circ} ; 90^{\circ}$ incr $10^{\circ}$ & 8 \\
\hline
\end{tabular}

Finally the following equation of reduction factor $\alpha$ is obtained:

$$
\alpha=-0.074+0.0003 \cdot f_{c}+0.488 \cdot \frac{P}{P 0}-0.002 \cdot \frac{L}{B}
$$

The effect of $f_{c}$ has an increasing influence on the flexural stiffness of the slender column.This was already predicted and proven in [19] which presented the effect and impact of this strength on the general behavior of corner columns. In addition to the axial load level, it has an increasing effect on the $E I$ of the column. The expression also indicates that a decrease in the $E I$ value occurs as slenderness ration $(L / B)$ ratio is increased.

\section{VALIDATION}

For the experimentation of the proposed model a test series has been realized to determine the variation of the reduction factor according to the influence of different parameters on the behavior of the RC slender columns. The proposed method has been realized according to the expression of the reduction factor for an ultimate compressive concrete strain equal to 0.003 because it gives the best results among all other values of strain levels which varied between 0.002 and 0.004 . The square cross section has dimensions $B_{I}=0$ and $B=300 \mathrm{~mm}$ and the $\mathrm{L}$ section $B_{l}=100 \mathrm{~nm}$ and $B=300 \mathrm{~mm}$. Five methods are considered in this work to predict the nominal capacity of the RC columns. The curves in Figure 5 show the comparison between the proposed method, the codes $[1,2]$, and the methods proposed in $[3,6,8]$. All respective equations are presented in Table II. A comparison between the proposed method, and that suggested by Bonet et al. in [6] for the L-shaped cross-section is presented in Figure 6(a) showing the variation of the reduction factor as a function of the relative eccentricity $\eta$. This coefficient presented by Bonet has been calculated as $\eta=e / 4 . i_{c}$, where $i_{c}$ is the radius of gyration of the concrete section with respect to the bending axis and $e$ is the first order eccentricity. The effective stiffness factor shows a non-linear behavior as a function of $\eta$. A second comparison with Bonet equation presented in Figure 6(b) shows the effect of $\rho$ on the $\alpha$ of the slender column with a different angle loading $\theta$. (a)

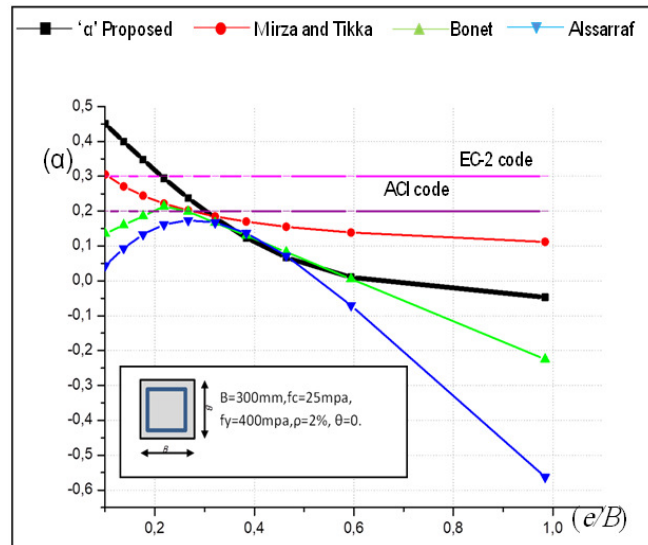

(b)

- ' $a$ ' Proposed. —- Mirza and Tikka. $\longrightarrow$ Bonet. $\longrightarrow$ Alssarr f

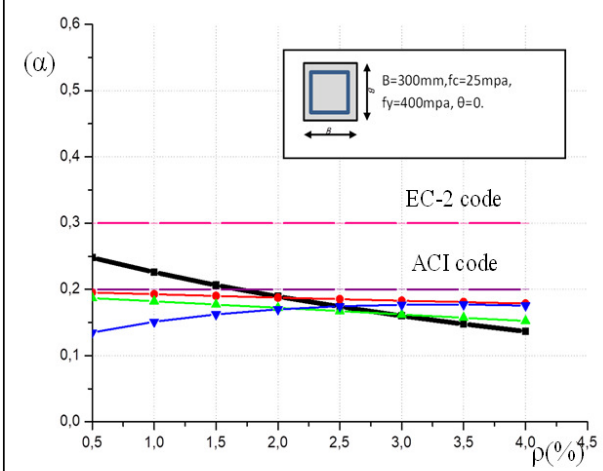

(c)
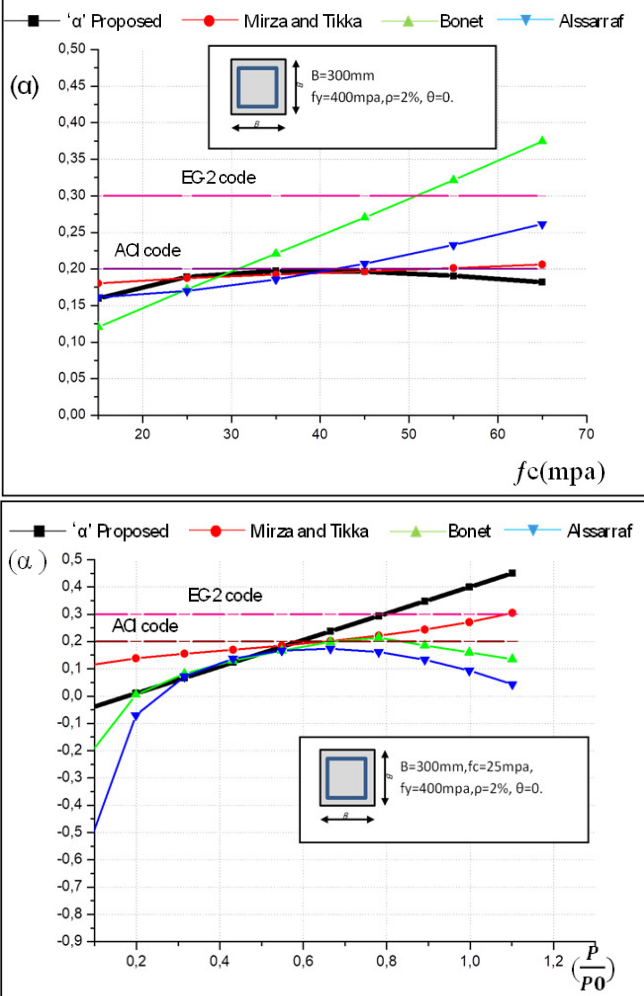

Fig. 5. Comparison of $\alpha$ with different authors and design codes for a square sections: Effect of (a) $e / B$, (b) $\rho$, (c) $f c$, and (d) of the axial loading ratio on the $\alpha$ of a slender column. 
(a)

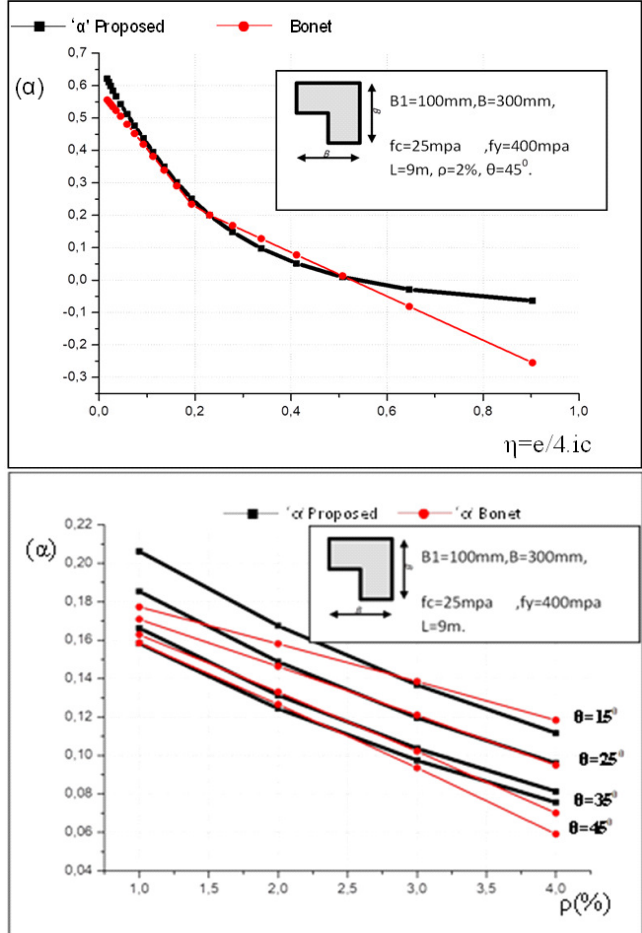

Fig. 6. Comparison between the Bonet equation and the proposed $\alpha$ for the L shaped section. (a) Effect of on $\alpha$ of the slender column, (b) effect of $\rho$ on $\alpha$ with a variation of angle loading $\theta$.

TABLE II. EI EQUATION COMPARISON

\begin{tabular}{|c|c|}
\hline Author & Effective flexural stiffness $E I$ \\
\hline Proposed & $\begin{array}{c}E I=\alpha E c I c+E s I s \\
\alpha=-0.074+0.0003 f_{c}+0.488\left(P / P_{0}\right)-0.002(1 / h)\end{array}$ \\
\hline [1] & $\begin{array}{c}E I=0.2 E c I c+E s I s / 1+\beta d \\
E I=0.4 E c I c / 1+\beta d\end{array}$ \\
\hline [2] & $\begin{array}{c}E I=K c \cdot E c \cdot I c+K s \cdot E s \cdot I s \\
\text { If } \rho l \geq 0.2 \%, K s=1, K c=(K 1 K 2) /(1+\phi e f f), K l=\sqrt{f_{c k} / 20, K_{2}=v} \\
\lambda_{\mathrm{m}} / 170 \\
\text { If } \rho l \geq 1 \%, K s=0, K c=0.3 / 1+0.5 \phi e f f\end{array}$ \\
\hline [17] & $\begin{array}{c}E I=(\alpha E c I c / 1+\phi e f f)+(E s I s / 1+\eta) \\
\alpha=(1.95-0.035 . \lambda m-0.25 \phi e f f)(\eta-0.2)+((f c / 225)+0.11)<0.1 \\
\text { if } \eta<0.2 \\
\alpha=(f c / 225+0.45)(\eta-0.2)+(f c / 225+0.11) k 0.1 ; \text { if } \eta \geq 0.2\end{array}$ \\
\hline [6] & $\begin{array}{c}E I=\alpha E c I c+0.8 E s I s \\
\alpha=0.47-0.35(e / h)(1 / 1+\beta(e / h))+0.003(1 / h) \\
\text { where } \beta=7.0 \text { for } \rho r s \leq 2 \% ; \text { and } \beta=8.0 \\
\text { for } \rho r s>2 \% .\end{array}$ \\
\hline [8] & $\begin{array}{c}E I=\alpha E c I c+E S I s \\
\alpha=0.38-0.011(1 / h)-1.3(e / h)+0.45\left(1-\left(P / P_{0}\right)^{2}\right) \\
0.1 \leq \alpha \leq 0.85\end{array}$ \\
\hline
\end{tabular}

$E I=$ flexural stiffness of compression member, $E c=$ modulus of elasticity of concrete, $E s=$ modulus of elasticity of reinforcement, $I c=$ moment of inertia of gross concrete section, $I s=$ moment of inertia of reinforcement, $P=$ axial load, $P_{0}=$ maximum load capacity, $e / h=$ eccentricity ratio, $l / h=$ geometrical slenderness ratio, $\beta d=$ ratio of the maximum factored axial sustained load to the maximum factored axial load associated with the same load combination, $v=$ relative normal force, $\lambda m=$ mechanical slendernes ratio, $\phi$ eff $=$ effective creep ratio, $f \mathrm{c}=$ concrete strength, $\rho l=$ geometrical reinforcement ratio, $f \mathrm{ck}=$ characteristic compressive cylinder strength of concrete at 28 days.

\section{RESULTS AND DISCUSSION}

This paper presents a statistical evaluation of the parameters that affect the flexural stiffness of slender columns subjected to short term loads with biaxial bending. Five methods $[1-3,6,8]$ for this comparison were considered to predict effective rigidity. In order to verify (9), variations of the $e / B, P / P_{0}, \rho$, and $f_{c}$ were used. These parameters are the most appeared in the expressions proposed in the literature. It can be noticed that both design codes propose an effective stiffness factor $\alpha$ independent of all the parameters (Figure 5), however other authors include the dependence of $\alpha$. In general an equation of $\alpha$ is proposed that decreases with $e / B$ and $\rho$ and increases with $f c$ and $P / P_{0}$. The proposed equation confirms this behavior of $\alpha$. The majority of tests considered the square cross section, with the exception of Bonet's expression which considered a cross section shape. A very large correspondence can be noticed between the Bonet's equation and the proposed equation (Figure 6) despite that Bonet's is nonlinear and the proposed expression is perfectly linear. Liu et al. [9] proposed a reduction stiffness factor $\alpha_{e}$ taking all the rigidity EI of the material, not only the concrete material of RC slender columns. The calculation model of columns has an $\mathrm{L}$ section of $600 \times 600 \times 200 \mathrm{~mm}$. The cross section details and dimensions of the specimen are shown in the Table III. The stiffness reduction factors calculated with Liu formulation and the flexural stiffness $E I$ corresponding for each axial load level are shown in Table IV. A comparison of the results of Liu with the flexural stiffness calculated with the proposed equation shows a good degree of accuracy between the results of Liu and the proposed equation (Figure 7). An average ratio of 0.983 was achieved.

TABLE III. GEOMETRY AND DIMENSIOS OF THE SPECIMENS IN [9]

\begin{tabular}{|c|c|}
\hline Column characteristic & Values \\
\hline$B_{1}(\mathrm{~mm})$ & 400 \\
\hline$B(\mathrm{~mm})$ & 600 \\
\hline$D c(\mathbf{m m})$ & 30 \\
\hline$\rho(\%)$ & 2.512 \\
\hline$f \mathrm{c}(\mathrm{mpa})$ & 14.3 \\
\hline$f y$ (mpa) & 360 \\
\hline$L(\mathrm{~mm})$ & 2900 \\
\hline$\theta\left({ }^{\circ}\right)$ & 45 \\
\hline$E c(\mathrm{mPa})$ & 30000 \\
\hline$E s(\mathrm{mPa})$ & 200000 \\
\hline$E I=E c I c+E s I s\left(K N \cdot m^{2}\right)$ & 77686 \\
\hline
\end{tabular}

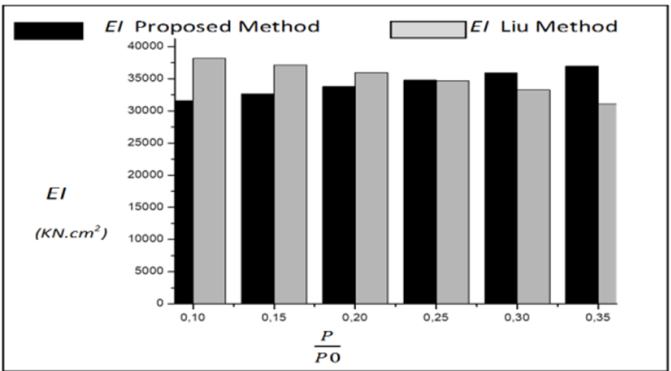

Fig. 7. Comparison of the proposed EI and the one of [9].

TABLE IV. VERIFICATION OF THE PROPOSED EQUATION WITH [9]

\begin{tabular}{|c|c|c|c|c|}
\hline $\begin{array}{c}\text { Axial load } \\
\text { level }\end{array}$ & $\boldsymbol{\alpha}_{e}$ & $\begin{array}{c}\boldsymbol{E I}_{\text {liu }}=\boldsymbol{\alpha}_{\boldsymbol{e}} \cdot \boldsymbol{E I} \\
\left(\mathbf{K N} . \mathbf{m}^{2}\right)\end{array}$ & $\begin{array}{c}\boldsymbol{E I}_{\text {prop }} \\
\left(\mathbf{K N . m}^{\mathbf{2}}\right)\end{array}$ & $\boldsymbol{E I}_{\text {prop }} / \boldsymbol{E I}_{\text {Liu }}$ \\
\hline 0.10 & 0.4915 & 38182 & 31587 & 0.83 \\
\hline 0.15 & 0.4782 & 37149 & 32662 & 0.87 \\
\hline 0.20 & 0.4630 & 35968 & 33787 & 0.94 \\
\hline 0.25 & 0.4464 & 34679 & 34790 & 1.00 \\
\hline 0.30 & 0.4281 & 33257 & 35914 & 1.07 \\
\hline 0.35 & 0.3996 & 31043 & 36981 & 1.19 \\
\hline Average & \multicolumn{3}{|r}{} & 0.983 \\
\hline
\end{tabular}




\section{CONCLUSION}

An iterative numerical procedure for the stiffness analysis and design of slender RC columns with square and L-shaped cross-sections under biaxial bending and axial loading using the unconfined Kent and Park stress is presented in this paper. The computational procedure takes into account the nonlinear behavior of the materials and includes the second order effects due to the additional eccentricity of the axial loading as applied by the moment-amplification method. The new equation suggested in this work is among the simplest proposed equations and its implementation is very easy to solve by manual calculation in a relatively short time. The concrete strength, the level of axial load, and the column slender ratio have been identified as the most important factors affecting the reduction coefficients and the effective bending stiffness $E I$. The formulation of the proposed method has been tested by comparison with other reported formulations. The results show that a good degree of accuracy and agreement has been achieved.

\section{REFERENCES}

[1] ACI 318-08: Building Code Requirements for Structural Concrete and Commentary. ACI, 2008

[2] EN 1992-1-1:2004 - Eurocode 2: Design of concrete structures - Part 11: General rules and rules for. Brussels, Belgium: CEN, 2004.

[3] C. S. Whitney and E. Cohen, "Guide for Ultimate Strength Design of Reinforced Concrete," Journal Proceedings, vol. 53, no. 11, pp. 455490, Nov. 1956, https://doi.org/10.14359/11524.

[4] B. Bresler, "Design Criteria for Reinforced Concrete Columns under Axial Load and Biaxial Bending," ACI Journal, Proceedings, vol. 10, no. 6, pp. 481-490, Jan. 2005.

[5] M. Khuntia and S. K. Ghosh, "Flexural Stiffness of Reinforced Concrete Columns and Beams: Experimental Verification," ACI Structural Journal, vol. 10, no. 3, May 2004.

[6] J. L. Bonet, M. L. Romero, and P. F. Miguel, "Effective flexural stiffness of slender reinforced concrete columns under axial forces and biaxial bending," Engineering Structures, vol. 33, no. 3, pp. 881-893, Mar. 2011, https://doi.org/10.1016/j.engstruct.2010.12.009.

[7] M. Resheidat, M. Ghanma, C. Sutton, and W.-F. Chen, "Flexural rigidity of biaxially loaded reinforced concrete rectangular column sections," Computers \& Structures, vol. 55, no. 4, pp. 601-614, May 1995, https://doi.org/10.1016/0045-7949(94)00493-M.

[8] S. Z. Al-Sarraf, I. A. S. Al-Shaarbaf, B. R. Al-Bakri, and K. F. Sarsam, "Flexural Rigidity of Slender RC Columns," Engineering and Technology Journal, vol. 27, no. 1, pp. 96-116, 2009.

[9] J. Liu, Y. Zhang, and P. Luo, "Flexural Stiffness Reduction Factor of Reinforced Concrete Column with Equal L-Shaped Section," in The Twelfth COTA International Conference of Transportation Professionals, Dec. 2012, pp. 3187-3193, https://doi.org/10.1061/ 9780784412442.325

[10] X. Feng, M. Shen, C. Sun, J. Chen, and P. Luo, "Research on Flexural Stiffness Reduction Factor of Reinforced Concrete Column with Equiaxial + Shaped Section," Procedia - Social and Behavioral Sciences, vol. 96, pp. 168-174, Nov. 2013, https://doi.org/10.1016/ j.sbspro.2013.08.022.

[11] Ö. Avşar, B. Bayhan, and A. Yakut, "Effective flexural rigidities for ordinary reinforced concrete columns and beams," The Structural Design of Tall and Special Buildings, vol. 23, no. 6, pp. 463-482, 2014 , https://doi.org/10.1002/tal.1056.

[12] N. Caglar, A. Demir, H. Ozturk, and A. Akkaya, "A simple formulation for effective flexural stiffness of circular reinforced concrete columns," Engineering Applications of Artificial Intelligence, vol. 38, pp. 79-87, Feb. 2015, https://doi.org/10.1016/j.engappai.2014.10.011.
[13] L. N. Ramamurthy and T. A. H. Khan, "L-Shaped Column Design for Biaxial Eccentricity," Journal of Structural Engineering, vol. 109, no. 8, pp. 1903-1917, Aug. 1983, https://doi.org/10.1061/(ASCE)07339445(1983)109:8(1903).

[14] Mallikarjuna and P. Mahadevappa, "Computer aided analysis of reinforced concrete columns subjected to axial compression and bending-I L-shaped sections," Computers \& Structures, vol. 44, no. 5, pp. 1121-1138, Aug. 1992, https://doi.org/10.1016/0045-7949(92) 90333-U.

[15] W. H. Taso and C.-T. T. Hsu, "Behaviour of biaxially loaded square and L-shaped slender reinforced concrete columns," Magazine of Concrete Research, vol. 46, no. 169, pp. 257-267, Dec. 1994, https://doi.org/ 10.1680/macr.1994.46.169.257.

[16] C. Dundar, S. Tokgoz, A. K. Tanrikulu, and T. Baran, "Behaviour of reinforced and concrete-encased composite columns subjected to biaxial bending and axial load," Building and Environment, vol. 43, no. 6, pp. 1109-1120, Jun. 2008, https://doi.org/10.1016/j.buildenv.2007.02.010.

[17] D. C. Kent and R. Park, "Flexural Members with Confined Concrete," Journal of the Structural Division, vol. 97, no. 7, pp. 1969-1990, 1971.

[18] H. Wang, Y. Zhang, and S. Qin, "A Study on Ductility of Prestressed Concrete Pier Based on Response Surface Methodology," Engineering, Technology \& Applied Science Research, vol. 6, no. 6, pp. 1253-1257, Dec. 2016, https://doi.org/10.48084/etasr.855.

[19] A. Ali, Z. Soomro, S. Iqbal, N. Bhatti, and A. F. Abro, "Prediction of Corner Columns' Load Capacity Using Composite Material Analogy," Engineering, Technology \& Applied Science Research, vol. 8, no. 2, pp. 2745-2749, Apr. 2018, https://doi.org/10.48084/etasr.1879. 